\title{
INTERVENTION FOR STRESS AMONG PUBLIC ADMINISTRATION UNDERGRADUATES IN NIGERIAN UNIVERSITIES
}

\section{OTU, OTU AKANU ${ }^{1}$, AROH, PATRICIA NWAMAKA ${ }^{2 *}$, OME SAMUEL OKECHUKWU ${ }^{3}$, EZEMA, LUKE CHIZOBA ${ }^{4} \&$ NWANGWU, TOCHUKWU LONGINUS ${ }^{5}$}

${ }^{1}$ Department of Political-Science, Alex Ekwueme Federal University, Ndufu-Alike Ebonyi State, Nigeria

${ }^{5}$ Department of Educational Foundations, University of Nigeria, Nsukka

${ }^{2,3,4}$ Department of Social-Science Education, University of Nigeria, Nsukka

\section{ABSTRACT}

This study examined the influence of Stress on Public Administration Undergraduates and the Usefulness of a Yoga Therapy (YT) in relieving this problem among these students. The study comprised of 494 public administration undergraduates. 57 of them showed extreme stress (32 experimental group; 25 control group). DHFS Wellness perceived Stress Scale of 10 items developed by Cohen (1983), structured on a five-point rating scale was adapted and used for data collection. Common stressors were also documented and stated in line with its severity. The Cronbach alpha coefficient reliability was 0.82. Parametric statistics of t-test and one-way ANOVA was employed to analyze the data. The results showed a significant high level of stress among public administration students. The mean stress level at pre-test between undergraduates in the experimental and control groups showed no significant difference $(U=47.00, p=0.361)$. YT was revealed to be significantly suitable for stress management among public administration undergraduates as evidenced to significant improvements in their post-test $(27 \pm 4.77)$ and follow-up $(21 \pm 2.64)$ mean stress scores in relation to the pre-test. KEYWORDS: Stress, Public Administration Students, Public Administration, Nigeria

Received: Jun 10, 2020; Accepted: Jun 30, 2020; Published: Jul 27, 2020; Paper Id.: IJMPERDJUN2020479

\section{INTRODUCTION}

Stress is an unavoidable phenomenon in every human being in so far as survival characterized man. Most of duty calls to the hospital were acclaimed to be stress-related problems [1]. As such, stress is an arching global discourse since it affects human physic and psycho-social feelings [2]. According to Reference [3] stress is not only an issue in work places; it is also a peculiar element experienced by students in schools, with public administration undergraduates not being an exception.

Perhaps, the aims of public administration are to prepare public administrators to: practice skillful and evidence-based public service; conduct and communicate program evaluations and policy analyses that inform the diverse fields within public service; and provide interdisciplinary expertise in the service of academic, professional, and community-based public service organizations [4]. According to the portal, the program also provides students with a public service perspective to lead and manage organizations, understand and contribute to public policy, critically analyze policies, programs, problems, and issues and make pertinent recommendations and communicate effectively in oral and written discourse with a diverse and changing workforce and public.

Notwithstanding, public administration students experience various stressors in the school ranging from writing exams, lack of recreational activities, inadequate water and power supply, poor classroom facilities, poor feeding and financial constraints. For instance, in the United States, between 2006 and 2013, evidence shows that 
many students experienced stress daily that had led to thoughts of suicide [5]. The disorder is similar in Nigeria as with other emergent nations [6]. Reference [7] discovered that students undergo extra stress than the entire populace, but rarely do they look for support. Supporting students especially, would be public administrators with an intervention such as yoga therapy that could help ease burden of stress becomes necessary due to the nature of their profession aimed at serving the public.

Yoga therapy is necessary because it is a system remedy that mixes one's physical and psycho-social contents to enhance facets of healthiness, mainly stress associated bugs [8]. Evidences have revealed the use of YT in containing stress ([9; 10]). Studies indicated that stress adds to various protracted disorders and ailments [11]. Therefore, the need to examine the influence of stress on public administration undergraduates, and the usefulness of YT in tackling this problem among these students is paramount.

\section{METHOD}

This study was carried out in line with the terms of the Helsinki Declaration. Participants' permission was obtained prior to the commencement of this study. 494 public administration undergraduates from first to final year of study participated in this study. 57 of them identified with extreme stress (scored 42 and above in the DHFS Wellness perceived Stress Scale at pretest) from the chosen South-Eastern Universities in Nigerian were involved (32 experimental; 25 control group). Other mode of involvement comprise: undergraduate public administration students not experiencing YT or inflicted with any chronic disease. $G^{*}$ power computer software [12] was used to ascertain the least sample size with statistical power, $\alpha=$ 0.68. Random Allocation Software (RAS) was used to assign participants to each group [13]. A modified DHFS Wellness perceived Stress Scale [14] was used for data collection. The DHFS is a well-validated and reliable 10 item questionnaire structured on a five point rating scale [14]. Time between pretest and post-test was 4 weeks while that of posttest data collection and follow-up evaluation took 8 weeks. Cronbach alpha reliability coefficient is 0.82 . As individuals' scores progresses on the DHFS scale, so their stress level. Questionnaire was used to elicit demographic information such as sex, age, level of study and level of stress. A tested therapy for reducing stress-YT [15]-was used to help the public administration undergraduates in the treatment group to contain stress issues for 8 weeks.

Participants in the yoga group attended a six-week Hatha yoga intervention. Group classes lasted one hour and were held twice a week. Each class began with 10 minutes of active breath work, followed by 45 minutes of physical postures and the last 5 minutes of class ended with a guided meditation. Participants were advised to listen to their bodies and not go beyond their physical limits. Seats, slabs and belts were available as needed, and the instructors demonstrated how to modify poses for those individuals unable to perform a given posture/exercise. While the control group executed six-weeks of computer-based mental exercise using Lumosity which hire a range of computer games to task memory, attention and problem-solving skills (Available online).

Prior to the analysis, items numbers 2, 3 and 6 received positive response and were scored reversely before totaling the items for each respondent, based on the scoring guide of the scale. Data was analyzed using parametric statistics to describe the demographic data. SPSS version 23 and one way ANOVA was used to ascertain the effects of treatment and time $\mathrm{x}$ group interaction effects. 


\section{RESULTS}

494 identified public administration undergraduates met the criteria for involvement and thus were included in this study, $24 \%$ of the students got stressed up extremely. The difference in the mean age between the treatment group (22.25 \pm 2.80$)$ and control group $(23.42 \pm 1.68)$ was not significant prior to administering YT intervention. Most of the participants were females and above 20 years old (23(67\%) and 24(72\%) generally in that order) and $1^{\text {st }}$ year students were higher than other levels (42\% total). The effect of the variable was evenly distributed across the groups as shown by the non-significant Chisquare test results.

At pretest, the result of $\%$ test revealed that mean stress level of the two groups were alike, as there was no significant difference in the stress scores gotten by students in either of the groups \%=78.0). As such, any variation detected in the groups stress level at post-test and follow-up may be attributed to YT.

The one way ANOVA result indicated a significant overall main effect of time $(\mathrm{F}(2,48)=162.252, P<0.001, \eta p 2$ $=0.833)$ on public administration students' stress scores as recorded by DHFS, with Time 2 (32.19 \pm 10.76$)$ and Time 3 $(29.46 \pm 14.37)$. This established the efficacy of YT in reducing stress among public administration undergraduates. Equally, a significant main effect of group exist $(\mathrm{F}(1,31)=141.179, P<0.001, \eta p 2=0.884)$ on students' stress scores: treatment group $(29.62 \pm 14.87)$ and control group $(45.43 \pm 3.85)$ Therefore, one infers that a significant difference exist in the mean stress scores of the groups as shown in the level of stress among public administration students in the treatment group trained with YT. Again, ANOVA result indicated that the group interaction was significant $(F(2,44)=138.761, P<$ $0.001, \eta p 2=0.794)$. This shown that the participants level of stress was affected over time subject to one's group.

A post-hoc analysis was carried out using eta-squared owing to significant difference in the main effects within and between the groups. The result indicated that public administration students in the treatment group administered YT showed a significant difference in their mean scores on stress over time, with $\mathrm{P}<0.001$. Adversely, the control group had no significant change in their mean stress scores over time $\mathrm{P}>0.05$. The result is in tandem with the hypothesis positing YT as being useful in managing stress among public administration undergraduates.

\section{DISCUSSION}

This study sought to explore the effect of stress on public administration undergraduates and the usefulness of YT in managing this crisis. The study indicated that $24 \%$ of the public administration students measured got extreme stress. This relates to previous findings that emphasized high rate of stress among students [7] and [6]. Therefore, managing the issue of stress so as to improve the emotional wellbeing of public administration undergraduates in the entire universe is imperative.

The present study showed no significant difference in mean stress at pre-test between the public administration undergraduates in the treatment and control groups in turn. However, the post-test and follow-up scores indicated a significant difference in the mean stress level for the experimental group compared to pre-test score of those of the control group. This finding entails that YT intervention was helpful in aiding public administration undergraduates to reduce stress. The findings concur with previous research that revealed the efficacy of YT as an intervention for solving psychological issues such as stress ([9]; [10]).

The present study is of theoretical and practical importance. Theoretically, it leans on James Lange theory of emotion. According to the theorists, when an event arouse a person, the autonomic nervous system reacts by creating 
physiological manifestations such as faster heart-beat, more perspiration, increased muscular tension, and stress. Emotional theory which research revealed its psychotherapeutic usefulness in treatment of maladaptive behaviors such as: stress [15]. More so, this study showed YT as a psychotherapeutic for stress management. Practically, researches have shown the worrying incidence of stress among undergraduates ([7;6]). However, seldom have studies provided therapeutic intervention to the issue of stress especially among Nigerian undergraduates. The sample size used in YT is small that generalization of the findings is limited. As such this study is subject to further research with a higher sample size. As levels of stress are shown to be increasing among students, [16] frequency of stress-related ailment is likely to ensue ([17; 18]). Therefore, future studies should continue to explore the relationship of stress and other psychosis in students. By implication, stress syndrome have been evidenced among public administration students, therefore, a therapeutic intervention such as YT is required by educators to effectively remediate these problems.

\section{CONCLUSIONS}

The study indicated that $24 \%$ of the public administration undergraduates surveyed were extremely stressed up. There was no significant difference in mean scores of stress at pre-test between the public administration undergraduates in the treatment and control groups. Finally, this study showed the usefulness of YT in helping public administration undergraduates manage stress. This is evidenced to significant progresses in their post-test and follow-up results. Therefore, for effective stress management among public administration undergraduates yoga therapy is required.

\section{REFERENCES}

1. Akinboye, J. O., Akinboye, D.O. and Adeyemo, A. O, (2012). Coping with Stress in Life and Work Place, Ibadan StirlingHoren Publishers Ltd.

2. Chandra, A. and Batada, A, (2006). Exploring Stress and Coping among African American Adolescents: The Shifting the Lens Study. Chronic Dis., 3 (2).

3. Sayiner, B, (2006). Stress Level of University Students. Bulletin of Istanbul Ticaret Universities Fen BilimleriDergisi, pp.2334.

4. Public Administration portal UNN

5. Hardy, M., (2013). Statistics on College Students" Stress, accessed March, 2013 from http://stress.lovetoknow.com

6. Eweniyi, G.B, (2009). Stress Management Skills and University Students" Academic Behaviour: Implications for Counseling. The Social Sciences, Scientific Research Publishing Company. Medwell Journals, 4(1), 139-142.

7. Stallman, H. M, (2008). Prevalence of Psychological Distress in University Students; Implications for Service Delivery. The Journal Australian Family Physicians.

8. Atkinson NL, Permuth-Levine R. (2009) Benefits, barriers, and cues to action of yoga practice: A focus group approach. Am J Health Behav. 33: 3-14.

9. Carson JW, Carson KM, Porter LS, Keefe FJ, Shaw H, Miller JM. (2007) Yoga for women with metastatic breast cancer: Results from a pilot study. J Pain Symptom Manage. 33:331-41.

10. Raghavendra RM, Nagarathna R, Nagendra HR, Gopinath KS, Srinath BS, Ravi BD, et al. (2007) Effects of an integrated yoga programme on chemotherapy-induced nausea and emesis in breast cancer patients. Eur Cancer Care (Engl) 16:462-74.

11. Granath J, Ingvarsson S, von Thiele U, Lundberg U. (2006). Stress management: A randomized study of cognitive behavioural therapy and yoga. Cogn.BehavTher. 35:3-10. 
12. Beck, T. W. (2013). The importance of a priori sample size estimation in strength and conditioning research. Journal of Strength and Conditioning Research, 27(8), 2323-2337.

13. Saghaei M. (2004) Random allocation software for parallel group randomized trials. BMC Med Res Methodol. 4:26.

14. Kelly, G. \& Percival, M. (2010). Perceived stress scale. Health scene investigation. New York: McGraw-Hill.

15. Sarah Mae Sincero. James-Lange Theory of Emotion. (2012). Retrieved Mar 30, 2019 from Explorable.com: htt ps://explorable.com/james-lange-theory-of-emotion

16. Cassey L, Ling RP-T. (2014) Stress and wellbeing in Australia survey. Australian Psychological Society 2014.

17. Cohen S, Janicki-Deverts D, Miller GE (2007). Psychological stress and disease. JAMA; 298: 1685-1687

18. Segerstrom SC, Miller GE. (2004) Psychological stress and the human immune system: a meta-analytic study of 30 years of inquiry. Psychol Bull; 130: 601.

19. George, Aspridis., et al. "Assessment of e-Learning Methods in Public Administration. The Case of the Greek National School of Public Administration and Local Government." International Journal of Human Resource Management and Research (IJHRMR) 3.5 (2013): 19-36

20. Ahmed, Ayesha Sultana, and A. Mary Swarnalatha. "Review on Usage of New Media, Among Undergraduate Students." International Journal of Computer Science and Engineering (IJCSE) 7.1 (2018): 1-8.

21. Chinyere, Ndukwe, Ikechukwu Ogeze Ukeje, and Johnpaul Chukwujindu Onele. "Leadership Styles and the Politics of Institutional Management of State-Owned Universities in Nigeria: Empirical Evidence from EBSU, South-Eastern GeoPolitical Zone, Nigeria." International Journal of Humanities and Social Sciences (IJHSS) 4.6 (2015): 91-102.

22. Uzoegwu, P. N., and Cajetan Ikechukwu Egbe. "Inclusion of Entrepreneurship Education in the Curriculum of Nigerian Universities Forself Reliance: Challenges and Prospects." International Journal of English and Literature (IJEL) 4.6 (2014): 95-104. 

